\title{
Effects of $1 \%$ cyclopentolate hydrochloride on anterior segment parameters obtained with Pentacam in young adults
}

\author{
Efeitos do cloridrato ciclopentolato 1\% sobre os parâmetros do segmento anterior obtidos com Pentacam \\ em adultos jovens
}

Ceyhun Arici ${ }^{1}$, Adem Turk ${ }^{2}$, Osman Melih Ceylan ${ }^{3}$, Mehmet Kola², Volkan Hurmeric ${ }^{3}$

\begin{abstract}
Purpose: To investigate the effects of topically applied 1\% cyclopentolate hydrochloride on anterior segment parameters obtained with a Pentacam rotating Scheimpflug camera in healthy young adults.

Methods: Anterior segment analyses of 25 eyes from 25 young adults (Group 1), before and after $45 \mathrm{~min}$ of $1 \%$ cyclopentolate hydrochloride application, were performed. For a control group (cycloplegia-free, Group 2), 24 eyes of 24 age- and sex-matched healthy cases were evaluated twice at $45 \mathrm{~min}$ intervals. The results obtained from the groups were compared statistically.

Results: The mean ages of the groups were $23.04 \pm 3.42$ (range, 18-29) and $22.4 \pm$ 2.05 (range, 18-27) years for Groups 1 and 2, respectively ( $p=0.259$ ). In Group 1, measurements between the two analyses were significantly different for the values of anterior chamber depth (ACD), anterior chamber angle (ACA), and anterior chambervolume (ACV) $(p<0.05)$, whereas no statistical difference was found for the central corneal thickness (CCT) and keratometry (K1, K2) measurements. In Group 2 , none of these parameters were statistically different between the two analyses. Conclusions: Topically applied 1\% cyclopentolate hydrochloride caused an increase in the ACD and ACV values, and a decrease in the ACA value. However, it had no significant effect on the CCT and keratometry measurements. It is important to consider these effects when using the Pentacam device on young adults with cycloplegia and when applying it for various reasons.
\end{abstract}

Keywords: Biometry; Cornea; Corneal pachymetry; Cyclopentolate/administration and dosage; Techniques, measures, measurement equipment

\begin{abstract}
RESUMO
Objetivo: Pesquisar os efeitos do cloridrato de ciclopentolato a 1\%, aplicado topicamente, em parâmetros do segmento anteriormedidos com a câmera de Scheimpflug Pentacam em adultos jovens e saudáveis.

Métodos: A análise do segmento anterior, de 25 olhos de 25 jovens adultos (Grupo 1), antes e após 45 minutos da aplicação de cloridrato ciclopentolato a 1\%, foram realizados. Como grupo controle (sem cicloplegia, Grupo 2), 24 ol hos de 24 pacientes saudáveis pareados por idade e sexo, foram avaliados duas vezes em intervalos de 45 minutos. Os resultados obtidos com os grupos foram comparados estatisticamente. Resultados: A média de idade dos grupos foram 23,04 \pm 3,42 (18-29 anos) e 22,4 $\pm 2,05$ (18-27) anos, respectivamente $(p=0,259)$. No Grupo 1, as medidas entre os dois exames foram significativamente diferentes para os valores de profundidade da câmara ante$\operatorname{rior}(A C D)$, ângulo da câmara anterior (ACA), e do volume da câmara anterior ( $A C V$ ) ( $p<0,05$ para todos), enquanto que não foram diferentes para a espessura corneana central (CCT) e ceratometria valores (K1, K2). No Grupo 2, nenhum destes parâmetros foi diferente entre os dois exames.

Conclusões: Aplicação tópica de cloridrato de ciclopentolato a 1\% causou um aumento nos valores de ACD e ACV e uma diminuição nos valores da ACA. No entanto, ele não teve nenhum efeito significativo sobre as medidas de CCT e ceratometria. $E$ importante considerar esses efeitos sobre as medidas tomadas com Pentacam em adultos jovens com cicloplegia quando aplicá-las em diferentes situações.
\end{abstract}

Descritores: Biometria; Córnea; Paquimetria corneana;Ciclopentolato/administração \& dosagem; Técnicas, medidas, equipamentos de medição

\section{INTRODUCTION}

The assessment of anterior segment structures has become an important consideration for the planning of ocular refractive and cataract surgery, as well as for diagnosing and treating glaucoma and assessing corneal health ${ }^{(1-3)}$. This assessment is typically performed by means of slit lamp biomicroscopy in clinical applications. An objective quantitative assessment of anterior segment structures is not adequate, and direct iridocorneal angle visualization can only be achieved using diagnostic contact lenses. Recently introduced anterior segment imaging technologies, such as rotating Scheimpflug imaging and anterior segment optical coherence tomography, promise to overcome these limitations. They offer quantitative information and qualitative imaging of the cornea, anterior chamber, and iridocorneal angle $\mathrm{e}^{(1,4,5)}$.
Cycloplegic agents, which relax the ciliary muscle, are primarily used for detailed fundus examinations. They are also employed during surgery, refraction, and in the treatment of some ocular diseases, such as amblyopia, accommodative esotropia, and corneal traumas. In addition, they can also be used in the management of uveitis, in order to prevent adhesion of the iris. Their cycloplegic effects reduce ocular pain and photophobia in ocular inflammatory diseases ${ }^{(6-12)}$. Atropine, cyclopentolate, and tropicamide are the most commonly used cycloplegic agents. Atropine produces the greatest amount of cycloplegia, making it the gold standard, but its effects are prolonged, and it can produce severe side effects. In contrast, cyclopentolate and tropicamide have relatively short durations of action, so they are used widely in clinical practice ${ }^{(13-15)}$.
Submitted for publication: April 22, 2014

Accepted for publication: May 1, 2014

Study conducted at Gulhane Military Medical Faculty, Department of Ophthalmology.

Department of Ophthalmology, Cerrahpasa Faculty of Medicine, Istanbul University, Istanbul, Turkey.

Department of Ophthalmology, Faculty of Medicine, Karadeniz Technical University, Trabzon, Turkey.

3 Department of Ophthalmology, Gulhane Military Medical Academy, Ankara, Turkey.
Funding: No specific financial support was available for this study.

Disclosure of potential conflicts of interest: None of the authors have any potential conflicts of interest to disclose.

Corresponding author: Adem Turk. Karadeniz Technical University, School of Medicine, Department of Ophthalmology, 61080, Trabzon, Turkey - E-mail: doktorademturk@yahoo.com

Institution responsible for the approval of the Research Ethics Committee: Gulhane Military Medical Academy, Ankara, Turkey.

Project number: 1491-1337-11/1539. 
For clinical results that involve cycloplegia, for example in cyclopentolate-applied cases, it is important to determine how the condition influences anterior segment parameters. It is also important to determine whether the changes that can arise with cycloplegia pose a risk to patients. To the best of our knowledge, alterations to anterior segment parameters in young adults, as measured with the Pentacam device following cyclopentolate-induced cycloplegia, have not previously been reported in the literature. Therefore, we aimed to explore this issue in this prospective study.

\section{METHODS}

This prospective study, consisting of a case series of healthy young adult patients, was performed at the Gulhane Military Medical Faculty, Department of Ophthalmology, in Ankara, Turkey. Local ethics committee approval was granted for the study protocol and informed consent was obtained from all the participants.

The study involved young adult patients aged between 18 and 29 years, who applied to the ophthalmology polyclinic for refractive error examinations. Detailed demographic data was obtained and each participant was subjected to a comprehensive ophthalmologic examination. The best-corrected visual acuity of each patient was recorded using a Snellen chart. Slit lamp biomicroscopy, indirect fundus examinations, and intraocular pressure measurements (using a noncontact tonometer) were then performed.

The inclusion criteria were: no additional ocular pathologies other than refractive errors, with a best-corrected visual acuity of over 10/10 (on the Snellen scale) for both eyes; a refractive error (in spherical equivalent) within \pm 2.00 diopters; an intraocular pressure of $\leq 21 \mathrm{mmHg}$ in both eyes; a cup-to-disc (C/D) ratio of $\leq 0.4$ and a C/D ratio asymmetry of $\leq 0.2$ between the two eyes, without any retinal or optic disc anomalies as determined by a fundus examination. The exclusion criteria were: diseases that could affect measurements in either eye, such as corneal diseases, pterygium, cataracts, vitreous opacity, retinal diseases, strabismus, glaucoma, and nystagmus; a history of using topical/systemic medications; systemic diseases that could interfere with the eye structure; and an unwillingness to participate. Additionally, patients who had undergone prior eye surgery for any reason and who were not compliant during the measurements were excluded from the study. None of the participants had a history of contact lens use.

\section{Devices used in the Study}

Potec PRK-6000 (Potec Co. Ltd, Daejeon, Republic of Korea): This device is a tabletop autorefractometer that provides a rapid monocular refraction measurement using a touch-screen function.

Pentacam (Pentacam Rotating Scheimpflug Camera; Oculus, Wetzlar, Germany): This device can perform a complete measurement of the anterior eye segment in less than two seconds, combining a rotating Scheimpflug camera with a static camera to acquire multiple photographs of the anterior segment of the eye. The Scheimpflug camera rotates, along with a monochromatic slit light source, around the optical axis to obtain the slit images. This rotating system performs a corneal scan from $0^{\circ}$ to $180^{\circ}$, and each of the photographs represents an image of the cornea at a specific angle. The static camera is placed in the center to control fixation. During measurement, extraneous eye movements are detected by a static pupil camera, and are automatically corrected for during the calculation process. The photographs are used to reconstruct the anterior and posterior corneal topographies using height data. The device also analyzes the corneal central radii, corneal asphericity, various colored maps of curvature and elevation, corneal pachymetry, crystalline lens densitometry, and the complete anterior chamber (anterior chamber depth, volume, and angle). The measurements are all non-contact and are free of discomfort to the patient $t^{(1,5)}$.

\section{EXAMINATIONS}

All patients were divided into two groups. For Group 1, the refractive errors of both eyes of the patients were measured without cycloplegia, using the Potec PRK-6000. Anterior segment analyses of both eyes was then performed with the Pentacam device (first exam). Next, one drop of $1 \%$ cyclopentolate (Sikloplejin ${ }^{\circledR}$, Abdi Ibrahim, Istanbul, Turkey) was applied to both eyes of the patients. This application was repeated 5 min later. The presence of light activation in the pupils was checked 45 min after the first cyclopentolate application. No pupillary activity was observed in any of the Group 1 patients. All eye measurements were then repeated using both devices (second exam). For Group 2 (the cycloplegia-free control group), all patients were evaluated twice at 45-min intervals, using the same devices and under identical conditions.

For measurements with the Potec PRK-6000, the patients were asked to sit in a unit chair connected to the device, and to lean their foreheads and chins to relevant locations relative to the device. The Pentacam measurements were obtained in an environment with dim light. Patients assumed a seated position with their chins on the chin rest and their foreheads on the forehead bar, and they sat looking directly at the fixation target. The researcher who obtained the Pentacam measurements aligned and focused the images by monitoring the ocular images from a computer monitor over time, according to the manufacturer's instructions. This included defining the pupil edge and the central and corneal apices. To obtain a more objective image, the automatic release mode of the device was used. The device is capable of capturing a 25-slit image of the anterior chamber and preparing the corneal pachymeter map and anterior chamber analyses in less than two seconds.

The measurements from both groups were obtained by two investigators under the same conditions, with each device being used by the same investigator. All the measurements were repeated at least three times. The averaged results were used to calculate the refractive error and keratometry (K1, K2), central corneal thickness (CCT), anterior chamber depth (ACD), anterior chamber volume (ACV), and anterior chamber angle (ACA) values for a particular eye. The following formula was used for the calculation of the spherical equivalent: spherical equivalent $($ diopter $[D])=$ sphere $(D)+[\text { cylinder }(D) / 2]^{(16)}$.

\section{Statistical analysis}

The measurements obtained from one randomly selected eye from each subject in both groups were expressed as the mean \pm standard deviation. Statistical analyses were performed using SPSS software, version 13.0.1 (SPSS, Chicago, Illinois, USA; license no: 9069728, KTU, Trabzon, Turkey). Data normality was assessed using the Kolmogorov-Smirnov test. The measurements from the two examinations were compared with a paired samples t-test and an independent samples $t$-test in both groups. $P<0.05$ was considered as significant.

\section{RESULTS}

The study involved 49 eyes from 49 patients (31 male, 18 female). The mean age of the cycloplegia group (Group 1, n=25) was 23.04 \pm 3.42 years (range, 18-29), while the mean age of the control group (Group 2, n=24) was $22.4 \pm 2.05$ years (range, 18-27). There was no significant difference between the two groups in terms of age or sex distribution ( $P=0.259$ and $P=0.878$, respectively).

Table 1 provides a comparison of the refractive error values calculated in terms of keratometry and spherical equivalent (SE), as obtained during the two different exam sessions in both groups. No significant changes occurred in either group in terms of keratometry values (K1 and K2) between the first and second exams. However, a hyperemetropic shift was observed in Group 1 in terms of the refractive error values, while no similar significant changes were observed in Group 2. 
A comparison of the CCT, ACD, ACV, and ACA values obtained during the two different exams in both groups is provided in table 2. It was observed that no significant changes occurred in either group in terms of the CCT values between the first and second exams. Furthermore, no significant changes were observed in the Group 2 cases between the two exams in terms of the $A C D, A C V$, or $A C A$ values. However, the ACD and ACV values significantly increased, and the ACA values significantly decreased, in the Group 1 cases.

Table 1. The keratometric (K1 and K2) and spherical equivalent (SE) values obtained in two different measurement sessions for the cycloplegia group (Group 1) and the control group (Group 2)

\begin{tabular}{|c|c|c|c|c|}
\hline & Exam & Group $1(n=25)$ & Group $2(n=24)$ & $p$ value ${ }^{* *}$ \\
\hline \multirow[t]{5}{*}{ K1 (D) } & First & $42.97 \pm 1.2$ & $43.14 \pm 1.34$ & 0.6430 \\
\hline & & $(41-46)$ & $(39.9-45.7)$ & \\
\hline & Second & $42.97 \pm 1.19$ & $43.15 \pm 1.34$ & 0.6330 \\
\hline & & $(40.9-45.8)$ & $(40-45.7)$ & \\
\hline & $P$ values* & 0.832 & 0.627 & \\
\hline \multirow[t]{5}{*}{ K2 (D) } & First & $43.61 \pm 1.6$ & $44.01 \pm 1.42$ & 0.3550 \\
\hline & & $(41-46.6)$ & $(40.3-46.9)$ & \\
\hline & Second & $43.59 \pm 1.54$ & $44 \pm 1.42$ & 0.3410 \\
\hline & & $(40.9-46.6)$ & $(40.3-46.8)$ & \\
\hline & $P$ values* & 0.653 & 0.477 & \\
\hline \multirow[t]{5}{*}{ SE (D) } & First & $-0.71 \pm 0.64$ & $-0.44 \pm 0.43$ & 0.0900 \\
\hline & & $(-1.75-0.13)$ & $(-1-0.5)$ & \\
\hline & Second & $0.28 \pm 0.48$ & $-0.48 \pm 0.36$ & $<0.0001$ \\
\hline & & $(-0.5-0.75)$ & $(-1-0.25)$ & \\
\hline & $P$ values* & $<0.0001$ & 0.364 & \\
\hline
\end{tabular}

${ }^{*}=$ paired samples $t$-test; ${ }^{* *}=$ independent samples $t$-test.

Table 2. Results of the anterior segment measurements for the cycloplegia group (Group 1) and the control group (Group 2), as obtained in two different measurement sessions using the Pentacam device

\begin{tabular}{|c|c|c|c|c|}
\hline & Exam & Group $1(n=25)$ & Group $2(n=24)$ & $P$ value ${ }^{* *}$ \\
\hline \multirow{5}{*}{$\begin{array}{l}\text { Central corneal } \\
\text { thickness (CCT) } \\
(\mu \mathrm{m})\end{array}$} & First & $538.48 \pm 34.32$ & $557.42 \pm 33.51$ & 0.057 \\
\hline & & $(483-617)$ & $(492-610)$ & \\
\hline & Second & $538.12 \pm 33.3$ & $556.38 \pm 34.48$ & 0.066 \\
\hline & & $(484-610)$ & $(489-606)$ & \\
\hline & $P$ values & $0.706^{*}$ & $0.269^{*}$ & \\
\hline \multirow{5}{*}{$\begin{array}{l}\text { Anterior chamber } \\
\text { depth }(A C D)(m m)\end{array}$} & First & $3.08 \pm 0.34$ & $3.03 \pm 0.23$ & 0.569 \\
\hline & & $(2.02-3.54)$ & $(2.55-3.54)$ & \\
\hline & Second & $3.19 \pm 0.34$ & $3.02 \pm 0.23$ & 0.047 \\
\hline & & $(2.13-3.69)$ & $(2.54-3.51)$ & \\
\hline & $P$ values & $<0.0001 *$ & $0.441^{*}$ & \\
\hline \multirow{5}{*}{$\begin{array}{l}\text { Anterior } \\
\text { chamber angle } \\
\text { (ACA) (Degree) }\end{array}$} & First & $38.09 \pm 8.13$ & $39.19 \pm 4.28$ & 0.555 \\
\hline & & $(22.7-55.2)$ & $(32-47.3)$ & \\
\hline & Second & $33.95 \pm 10.14$ & $39.36 \pm 4.21$ & 0.020 \\
\hline & & $(15.1-49.3)$ & $(32.7-47.7)$ & \\
\hline & $P$ values & $<0.016^{*}$ & $0.631^{*}$ & \\
\hline \multirow{5}{*}{$\begin{array}{l}\text { Anterior } \\
\text { chamber volume } \\
(\mathrm{ACV})\left(\mathrm{mm}^{3}\right)\end{array}$} & First & $183.64 \pm 40.38$ & $172.92 \pm 23.15$ & 0.263 \\
\hline & & $(82-252)$ & $(136-236)$ & \\
\hline & Second & $190.96 \pm 37.89$ & $171.5 \pm 23.46$ & 0.037 \\
\hline & & $(100-273)$ & $(136-230)$ & \\
\hline & $P$ values & $<0.007^{*}$ & $0.183^{*}$ & \\
\hline
\end{tabular}

${ }^{*}=$ paired samples $t$-test; ${ }^{* *}=$ independent samples $t$-test.

\section{DISCUSSION}

Uncorrected refractive errors are among the most common causes of visual impairment in the world ${ }^{(17)}$. In clinical practice, the most frequently used methods of refractive error examination are retinoscopy and autorefraction. During refraction examinations in young adults, one of the most important concerns is control of the accommodative response. However, both retinoscopy and autorefraction can be negatively affected by the accommodative response in young phakic patients, frequently resulting in an overestimation of myopia and consequently in incorrect treatments ${ }^{(7,18)}$. Non-cycloplegic fogging and drug-induced cycloplegia are the most commonly used procedures for minimizing the effects of accommodation during refraction. In a previous study, it was found that the autorefractor's auto-fogging system did not appear to adequately neutralize the patient's accommodative activity, and the fixation target most likely induced instrument myopia ${ }^{(7)}$. The development of a significant hyperemetropic shift in the refractive error values in young adults with cycloplegia in our study, supports findings relating to the inadequacy of auto-fogging systems. In another study performed on young adults, significant differences were found between the cycloplegic and non-cycloplegic autorefraction values ${ }^{(7)}$. Thus, cycloplegic refraction examinations provided more reliable results in all age groups ${ }^{(17,19)}$.

Recent developments in imaging techniques allow the clinician to quantitatively calculate anterior segment parameters, such as keratometry, $C C T, A C D, A C V$, and $A C A^{(5,20)}$. Among these new technologies, the Pentacam device is a rotating Scheimpflug system that allows for the noninvasive assessment of the anterior chamber structures. It has been reported in various studies that this device provides a noninvasive, repeatable, and reliable method for anterior segment analysis of the eye ${ }^{(1,21)}$. In our study, the repeatability of the Pentacam device was found to be reliable because the repeated measurements of the control group cases were statistically similar.

ACD and keratometry measurements are used for several applications in clinical practice and an accurate intraocular lens (IOL) power calculation is very important for postoperative refraction analysis following cataract surgery. Preoperative measurements of ACD and keratometry are used in advanced $\mathrm{OOL}$ calculation formulas in order to determine the IOL power calculation ${ }^{(22)}$. An error of $0.1 \mathrm{~mm}$ in the ACD measurement results in a $0.1 \mathrm{D}$ error in the postoperative refraction calculation. Therefore, IOL calculation formulas that anticipate postoperative IOL positioning according to the $A C D$ require extremely precise preoperative $A C D$ and keratometry measurements ${ }^{(22,23)}$. Furthermore, the ACD must be considered before phakic IOL implantation ${ }^{(24)}$ and screening for primary angle closure glaucoma (PACG) ${ }^{(25)}$. In our study, it was observed that cyclopentolate-induced cycloplegia did not cause any significant changes in keratometry values, but it did result in a significant increase in ACD values. Therefore, such measurements may result in postoperative refractive errors in cataract patients, delayed glaucoma diagnoses in PACG patients, or corneal endothelial cell damage in phakic IOL patients, due to the closer positioning of the IOL to the corneal endothelium.

The ACV and ACA are other important anterior segment parameters in ocular pharmacokinetics and PACG development ${ }^{(26,27)}$. The cycloplegic effect of 1\% cyclopentolate results in the backward movement of the crystalline lens and a decrease in its thickness. This causes an increase in pupil diameter and a subsequently increase the ACD and ACV values ${ }^{(23,28)}$. In our study, it was observed that cyclopentolate-induced cycloplegia resulted in a significant increase in ACV readings and a significant decrease in ACA readings. The ACA decrease can be attributed to the iris being bunched up at an angle following the pupil dilatation ${ }^{(6)}$. Thus, an ACA assessment following cycloplegia could result in an inaccurate reading, i.e., too narrow. The impossibility of obtaining detailed imaging of angle structures with the Pentacam device represents a disadvantage of this technique. The reproducibility of ACA measurements using the Pentacam system may therefore be less than those obtained with UBM or gonioscopy ${ }^{(29)}$. 
The measurement of the CCT is another important factor in the assessment of patients with corneal diseases and glaucoma, and in screening for refractive surgery ${ }^{(26)}$. In our study, it was observed that cyclopentolate-induced cycloplegia caused no significant change in the CCT readings.

In a previously published study, the effect of cycloplegia caused by cyclopentolate application on anterior segment parameters obtained with the Pentacam device, was analyzed in a pediatric age group ${ }^{(23)}$. While no significant changes were observed in the mean keratometry or ACA values, a significant decrease was observed in the CCT, and significant increases were observed in the ACD and ACV values ${ }^{(23)}$. Furthermore, in a study analyzing the effects of single-dose $1 \%$ tropicamide in young adults, no significant changes were observed in keratometry or CCT values after the application. However, a significant increase was observed in the ACD and ACV measurements ${ }^{(30)}$. Interestingly, while no significant changes were observed in right-eye ACA values, a significant decrease was observed in the left-eye values. Thus, the significance of this study is difficult to determine due to the disagreement in the mean values of the ACA, and due to the fact that it did not use a control group ${ }^{(30)}$. In addition, the cycloplegic effects of one application of 1\% tropicamide are less than for two applications of $1 \%$ cyclopentolate ${ }^{(31)}$, as used in our study. Therefore, to our knowledge, this study is the first to use the Pentacam system to examine the anterior segment changes that arise in young adults following an efficient cycloplegic application.

The data obtained in this study are a combination of the cycloplegic and mydriatic effects of the application of $1 \%$ cyclopentolate. Various studies have reported changes to anterior segment parameters following mydriasis. One study, performed using anterior segment optical coherence tomography (OCT), observed a decrease in iris volume and an increase in ACA parameters (angle opening distance, trabecular iris angle, and trabecular iris space area) following pharmacological dilation (using 5\% phenylephrine hydrochloride and $0.8 \%$ tropicamide $)^{(32)}$. The same study also reported an increase in ACA parameters following mydriasis(32). Another study using OCT reported a similar decrease in iris volume following pharmacological dilation (using 1\% tropicamide or 10\% phenylephrine) in healthy eyes, but no significant changes to the ACA or ACD values ${ }^{(33)}$. In another study performed using UBM, an increase was observed in the ACA and ACD measurements after mydriasis (using 2\% ibopamine, $10 \%$ phenylephrine, and $1 \%$ tropicamide), but no significant change occurred in the corneal thickness ${ }^{(34)}$. This study also reported that the ACD increase could also be detected using an A-scan ultrasonographic examination ${ }^{(34)}$. Finally, an animal study performed using UBM also reported an increase in ACA values following mydriasis (using $0.5 \%$ tropicamide ${ }^{(35)}$. Here, the increase in ACA and ACV following pharmacological dilation was attributed to the backward movement of the iris lens diaphragm as a result of longitudinal ciliary muscle contraction ${ }^{(32)}$. In contrast to these studies, we observed a decrease in ACA values following pharmacological application. This is possibly due to the use of a Pentacam device for obtaining measurements. Also, unlike the above studies, the application of consecutive doses of $1 \%$ cyclopentolate produced both a cycloplegic and mydriatic effect.

The main aim of this study was to investigate the effects of $1 \%$ cyclopentate on eye measurements performed with a Pentacam device in healthy young adults without a high refractive error. Cases with an ocular refractive error above $\pm 2 \mathrm{D}$, or with ocular problems such as a narrow iridocorneal angle, glaucoma, or cataracts were excluded. The fact that the effects of cyclopentolate in such eyes were not investigated thus represents a limitation of the study.

In summary, the application of $1 \%$ cyclopentolate to the eyes of healthy young adults caused significant increases to both ACD and ACV measurements, and a decrease in the ACA measurement. Therefore, these effects on anterior segment parameters should be considered in a clinical setting, especially for cataract and refractive surgery applications, and glaucoma diagnosis.

\section{REFERENCES}

1. Ceylan OM, Turk A, Erdurman C, Mumcuoglu T, Erdem U, Gokce G, et al. Comparison of oculus pentacam and stratus optical coherence tomography for measurement of central corneal thickness. Cornea. 2011;30(6):670-4.

2. Ambrósio R Jr, Valbon BF, Faria-Correia F, Ramos I, Luz A. Scheimpflug imaging for laser refractive surgery. Curr Opin Ophthalmol. 2013;24(4):310-20.

3. Zhao Q, Li NY, Zhong XW. Determination of anterior segment changes with Pentacam after phacoemulsification in eyes with primary angle-closure glaucoma. Clin Experiment Ophthalmol. 2012;40(8):786-91

4. Konstantopoulos A, Hossain P, Anderson DF. Recent advances in ophthalmic anterior segment imaging: a new era for ophthalmic diagnosis? Br J Ophthalmol. 2007;91(4): 551-7.

5. Oliveira CM, Ribeiro C, Franco S. Corneal imaging with slit-scanning and Scheimpflug imaging techniques. Clin Exp Optom. 2011;94(1):33-42.

6. Lai JS, Gangwani RA. Medication-induced acute angle closure attack. Hong Kong Med J. 2012;18(2):139-45.

7. Jorge J, Queiros A, González-Méijome J, Fernandes P, Almeida JB, Parafita MA. The influence of cycloplegia in objective refraction. Ophthalmic Physiol Opt. 2005;25(4): 340-5.

8. Agrawal RV, Murthy S, Sangwan V, Biswas J. Current approach in diagnosis and management of anterior uveitis. Indian J Ophthalmol. 2010;58(1):11-9.

9. Torok PG, Mader TH. Corneal abrasions: diagnosis and management. Am Fam Physician. 1996;53(8):2521-9.

10. Janda AM. Ocular trauma. Triage and treatment. Postgrad Med. 1991;90(7):55-60.

11. Simone JN, Whitacre MM. Effects of anti-inflammatory drugs following cataract extraction. Curr Opin Ophthalmol. 2001;12(1):63-7.

12. Ortega-Usobiaga J, Cobo-Soriano R, Llovet F, Ramos F, Beltrán J, Baviera-Sabater J. Retreatment of hyperopia after primary hyperopic LASIK. J Refract Surg. 2007;23(2): 201-5.

13. Mohan K, Sharma A. Optimal dosage of cyclopentolate $1 \%$ for cycloplegic refraction in hypermetropes with brown irides. Indian J Ophthalmol. 2011;59(6):514-6.

14. Lovasik JV. Pharmacokinetics of topically applied cyclopentolate $\mathrm{HCl}$ and tropicamide. Am J Optom Physiol Opt. 1986;63(10):787-803.

15. Ebri A, Kuper H, Wedner S. Cost-effectiveness of cycloplegic agents: results of a randomized controlled trial in nigerian children. Invest Ophthalmol Vis Sci. 2007;48(3): 1025-31.

16. Arici C, Turk A, Keskin S, Ceylan OM, Mutlu FM, Altınsoy HI. Effect of cycloplegia on refractive errors measured with three different refractometers in school age children. Turk J Med Sci. 2012;42(4):657-65.

17. Hashemi H, Khabazkhoob M, Jafarzadehpur E, Yekta AA, Emamian MH, Shariati M, et al. High prevalence of myopia in an adult population, Shahroud, Iran. Optom Vis Sci. 2012:89(7):993-9.

18. Nayak BK, Ghose S, Singh JP. A comparison of cycloplegic and manifest refractions on the NR-1000F (an objective Auto Refractometer). Br J Ophthalmol. 1987;71(1):73-5.

19. Fotouhi A, Morgan IG, Iribarren R, Khabazkhoob M, Hashemi H. Validity of noncycloplegic refraction in the assessment of refractive errors: the Tehran Eye Study. Acta Ophthalmol. 2012;90(4):380-6.

20. Park SH, Choi SK, Lee D, Jun EJ, Kim JH. Corneal thickness measurement using Orbscan, Pentacam, Galilei, and ultrasound in normal and post-femtosecond laser in situ keratomileusis eyes. Cornea. 2012;31(9):978-82.

21. Shankar H, Taranath D, Santhirathelagan CT, Pesudovs K. Anterior segment biometry with the Pentacam: comprehensive assessment of repeatability of automated measurements. J Cataract Refract Surg. 2008:34(1):103-13.

22. Narváez J, Zimmerman G, Stulting RD, Chang DH. Accuracy of intraocular lens power prediction using the Hoffer Q, Holladay 1, Holladay 2, and SRK/T formulas. J Cataract Refract Surg. 2006;32(12):2050-3.

23. Palamar M, Egrilmez S, Uretmen O, Yagci A, Kose S. Influences of cyclopentolate hydrochloride on anterior segment parameters with Pentacam in children. Acta Ophthalmol. 2011;89(5):e461-5.

24. Vetrugno M, Cardascia N, Cardia L. Anterior chamber depth measured by two methods in myopic and hyperopic phakic IOL implant. Br J Ophthalmol. 2000;84(10):1113-6.

25. Yip JL, Foster PJ, Uranchimeg D, Javzandulam B, Javzansuren D, Munhzaya T, et al. Randomised controlled trial of screening and prophylactic treatment to prevent primary angle closure glaucoma. Br J Ophthalmol. 2010;94(11):1472-7.

26. Fu J, Wang X, Li S, Wu G, Wang N. Comparative study of anterior segment measurement with Pentacam and anterior segment optical coherence tomography. Can J Ophthalmol. 2010;45(6):627-31.

27. Rossi GC, Scudeller L, Delfino A, Raimondi M, Pezzotta S, Maccarone M, et al. Pentacam sensitivity and specificity in detecting occludable angles. Eur J Ophthalmol. 2012; 22(5):701-8.

28. Wendt M, Croft MA, McDonald J, Kaufman PL, Glasser A. Lens diameter and thickness as a function of age and pharmacologically stimulated accommodation in rhesus monkeys. Exp Eye Res. 2008;86(5):746-52.

29. Smith SD, Singh K, Lin SC, Chen PP, Chen TC, Francis BA, Jampel HD. Evaluation of the anterior chamber angle in glaucoma: a report by the American academy of ophthalmology. Ophthalmology. 2013;120(10):1985-97.

30. Palamar M, Alkan Z, Egrilmez S, Yagci A. Influences of tropicamide on anterior 
segment parameters with pentacam in healthy individuals. J Ocul Pharmacol Ther. 2013;29(3):349-52.

31. Hofmeister EM, Kaupp SE, Schallhorn SC. Comparison of tropicamide and cyclopentolate for cycloplegic refractions in myopic adult refractive surgery patients. J Cataract Refract Surg. 2005;31(4):694-700.

32. Mak H, Xu G, Leung CK. Imaging the iris with swept-source optical coherence tomography: relationship between iris volume and primary angle closure. Ophthalmology. 2013;120(12):2517-24.
33. Aptel F, Denis P. Optical coherence tomography quantitative analysis of iris volume changes after pharmacologic mydriasis. Ophthalmology. 2010;117(1):3-10.

34. Marchini G, Babighian S, Tosi R, Perfetti S, Bonomi L. Comparative study of the effects of $2 \%$ ibopamine, $10 \%$ phenylephrine, and $1 \%$ tropicamide on the anterior segment. Invest Ophthalmol Vis Sci. 2003;44(1):281-9.

35. Dulaurent T, Goulle F, Dulaurent A, Mentek M, Peiffer RL, Isard PF. Effect of mydriasis induced by topical instillations of $0.5 \%$ tropicamide on the anterior segment in normotensive dogs using ultrasound biomicroscopy. Vet Ophthalmol. 2012;15 Suppl 1:8-13.

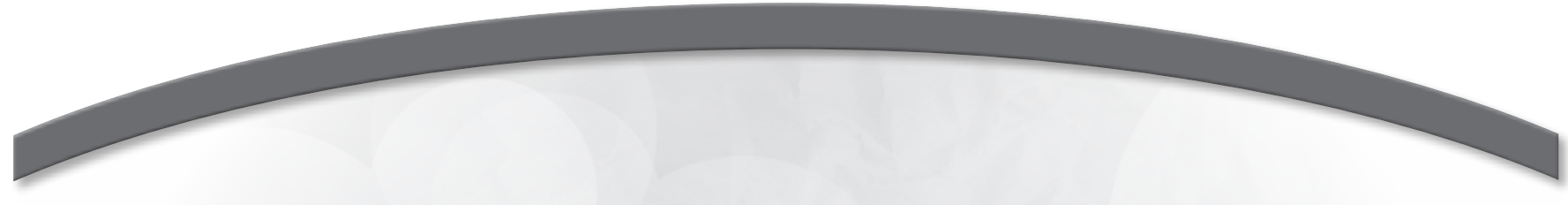

$17^{\circ}$ Congresso de Oftalmologia USP 16- Congresso de Auxiliar de Oftalmologia USP

\section{8 e 29 de novembro de 2014}

Centro de Convenções Rebouças

São Paulo - SP

\section{Informações:}

Tels.: (11) 5084-9174 / 5082-3030

E-mail: secretariausp@jdeeventos.com.br

Site: www.oftalmologiausp.com.br 